\title{
Validation of the Dutch guidelines for dual X-ray absorptiometry measurement
}

\author{
Noortje A Verdijk, Arnold C Romeijnders, Jos J Ruskus, Corien van der Sluijs, Victor J Pop
}

\author{
ABSTRACT \\ Background \\ In Europe, a case-finding strategy for osteoporosis is \\ recommended above widespread population-based \\ screening. However, no universally accepted policy \\ currently exists. In 2005, the Dutch College of General \\ Practitioners published guidelines for GPs to select \\ patients for dual energy X-ray absorptiometry (DXA). \\ Aim \\ To evaluate the sensitivity, specificity, and predictive \\ value of the Dutch guidelines to select participants with \\ osteoporosis for DXA. \\ Design of study \\ Cross-sectional. \\ Setting \\ A total of 345 females aged over 50 years (mean age $=$ \\ 62 years, standard deviation $[\mathrm{SD}]=8.3$ ) and 99 males \\ over 65 years of age (mean age $=72$ years, $S D=5.2$ ) \\ of a Dutch general practice. \\ Method \\ Calculation of sensitivity, specificity, positive predictive \\ value (PPV), and negative predictive value (NPV) of the \\ Dutch case-finding instrument for selecting patients \\ with osteoporosis for DXA measurement. \\ Results \\ Sensitivity was $19.5 \%$, specificity $85.6 \%$, PPV $18.6 \%$, \\ and NPV $86.6 \%$.

\section{Conclusion} \\ The Dutch guidelines are unreliable in detecting people \\ at risk for osteoporosis. \\ Keywords \\ DEXA scan; osteoporosis; practice guideline; predictive \\ value of tests; sensitivity and specificity.
}

\section{INTRODUCTION}

Osteoporosis is a major public health issue: osteoporotic fractures affect one in two women and one in five men aged $>50$ years. ${ }^{1}$ In 2000, the number of osteoporotic fractures in the European Union was estimated at 3.8 million, equalling a financial burden $€ 31.7$ billion. It is expected that by 2050, the direct cost of fractures in Europe will exceed $€ 75$ billion. $^{2}$ The annual incidence of fractures in the UK is estimated at 310000 with costs of $€ 2.4$ billion. $^{3}$ In the Netherlands over 430000 patients have osteoporosis ${ }^{4}$ and about 83000 people aged >55 years have a fragility fracture each year. ${ }^{5}$

Considering the growing incidence, fracture prevention and thus early diagnosis of osteoporosis are of great importance, especially since pharmacological treatment of osteoporosis has been shown to be cost-effective, irrespective of age. ${ }^{6}$ Diagnosis of osteoporosis is currently based on bone densitometry, usually by dual energy X-ray absorptiometry (DXA). Bone mineral density is widely recognised as a major predictor for fractures. ${ }^{7}$ However, case-finding strategy has been shown to be more cost-effective than population-based

NA Verdijk, MSc, PhD candidate; VJ Pop, professor of primary care, the Centre Of Research for Psychology in Somatic diseases, Medical Psychology and Neuropsychology, Tilburg University, Tilburg, the Netherlands. AC Romeijnders, GP, Coordination Centre of Nurse Practitioners for South East Netherlands, Veldhoven, the Netherlands. JJ Ruskus, GP; C van der Sluijs, GP, Primary Health Care Centre Riethoven, the Netherlands.

Address for correspondence

Noortje Verdijk, Tilburg University, The Centre for Research for Psychology in Somatic Diseases, PO Box 90153, 5000 LE Tilburg, Netherlands. E-mail: n.a.verdijk@uvt.nl

Submitted: 12 May 2008; Editor's response: 1 July 2008; final acceptance: 1 September 2008.

(C)British Journal of General Practice 2009; 59: 256-260.

DOI: 10.3399/bjgp09X420338 
screening of bone density, ${ }^{2,6}$ and is hence advocated by the World Health Organization $\left(\mathrm{WHO}^{8}\right.$ and in Europe. ${ }^{2,6}$ To date, several case-finding instruments have been developed and validated. ${ }^{9-18}$ However, there is no universally accepted policy.

In 2005, the Dutch College of General Practitioners published guidelines for GPs for the diagnosis and therapy of osteoporosis. ${ }^{19}$ According to suggestions in previous guidelines of the Dutch Institute for Health Care Improvement, ${ }^{5}$ they defined clinical decision rules to select patients for DXA, consisting of eight risk factors with weighted scores (Table 1). When a cut-off score of 4 is reached, referral for bone densitometry is advised. Although this case-finding instrument is widely used in general practice in the Netherlands, it has never been validated. Therefore, the research question of the current study is to investigate sensitivity, specificity, and predictive value of the Dutch case-finding instrument for selecting patients with osteoporosis for bone mineral density testing by DXA.

\section{METHOD}

Over a period of 6 months, 444 patients aged $>50$ years (345 females and 99 males) of a Dutch general practice (without known diagnosis of osteoporosis or terminal illness) were invited for DXA measurement. Eligible patients were all female patients aged $50-85$ years and male patients aged 65-85 years. These cut-offs were based on the knowledge that declining bone mineral density in females reaches thresholds that indicate osteoporosis from the age of 50 years. ${ }^{20}$ For males, a cut-off of 65 years was defined because, in general, fracture risk increases greatly after this age. ${ }^{6}$ Bone mineral density measurements were collected at the total hip, femoral neck, and lumbar spine using DXA technology (Hologic QDR 4500W, version 12.4). Values were expressed in $\mathrm{T}$ scores (that is, using standard deviations [SDs] from the young adult normal mean) and Z scores (that is, using SDs from the age- and sex-adjusted mean) based on the National Health and Nutrition Examination Survey database references for the hip and Hologic database references for the spine. In addition, participants were asked to fill in a questionnaire, consisting of 10 questions regarding risk factors for osteoporosis according to Dutch guidelines for casefinding, in interrogative form; for example, 'Have you suffered from a fracture after the age of 50 years? (yes/no)'. Finally, information was gathered on demographic characteristics.

A total risk score of the questionnaire was calculated based on the weighted scores of the Dutch case-finding instrument (Table 1). According to the Dutch guidelines for case finding, the cut-off

\section{How this fits in}

Although in Europe a case-finding strategy for osteoporosis is recommended above widespread population-based screening, no universally accepted policy exists so far. The Dutch case-finding instrument is widely used in the

Netherlands by GPs to select patients for dual energy X-ray absorptiometry, although it has never been validated. This study shows that the Dutch guidelines are unreliable in detecting patients at risk for osteoporosis. Due to ageing of the population and the growing incidence of osteoporosis, there is a need for further research to develop a more appropriate case-finding procedure to detect osteoporosis.

score was defined at four points.

First, bone mineral density was defined according to $\mathrm{WHO}$ criteria $^{21}$ as normal ( $\mathrm{T}$ score $\geq-1.0$ ), osteopenic ( $T$ score $<-1.0$ and $>-2.5$ ), or osteoporotic (T score $\leq-2.5$ ). Second, bone mineral density was defined according to the Dutch guidelines. In patients aged $<70$ years the WHO criteria $^{21}$ were used; in patients aged $\geq 70$ years, a $Z$ score below -1.0 was used to define osteoporosis. ${ }^{5,19}$ Z-score above -1.0 represented normal bone mineral density. Osteopenia was not defined within this age group.

Based on the diagnosis according to bone mineral density levels and the risk score according to the Dutch case-finding instrument, sensitivity, specificity, positive predictive value (PPV), and negative predictive value (NPV) were calculated. Ninety-five per cent confidence intervals $(95 \% \mathrm{Cl})$ were calculated using binomial expansion. Statistical analyses were performed using SPSS software (version 14.0). All analyses were carried out on the total research population, and for males and females separately.

\section{RESULTS}

Written informed consent was received from 234 females and 65 males (response rate $67 \%$ ). This loss was not selective as there were no significant

Table 1. Dutch case-finding instrument for dual energy $X$ ray absorptiometry measurement: ${ }^{19}$ recommended if total risk score $\geq 4$.

\begin{tabular}{lcc} 
Risk factor & Score & Sex \\
\hline Established vertebral fracture & 4 & $\mathrm{M}, \mathrm{F}$ \\
\hline Long-term use of high-dose corticosteroids $(>3$ months; $>7 \cdot 5 \mathrm{mg} /$ day $)$ & 4 & $\mathrm{M}, \mathrm{F}$ \\
\hline Fracture after age of 50 years & 4 & $\mathrm{~F}$ \\
\hline Age $>70$ years & 2 & $\mathrm{~F}$ \\
\hline Age $>60$ years & 1 & $\mathrm{~F}$ \\
\hline Hip fracture in first-degree family member & 1 & $\mathrm{~F}$ \\
\hline Weight $<60 \mathrm{~kg}$ & 1 & $\mathrm{~F}$ \\
\hline Severe immobility & 1 & $\mathrm{~F}$ \\
\hline
\end{tabular}




\begin{tabular}{|c|c|c|c|}
\hline & Total population $(n=290)$ & Females $(n=226)$ & Males $(n=64)$ \\
\hline Age in years, mean (SD) & $63.3(8.8)$ & $61.3(8.3)$ & $71.7(5.2)$ \\
\hline \multicolumn{4}{|l|}{ Risk factors guidelines, $n$ (\%) } \\
\hline Established vertebral fracture & $4(1.4)$ & $2(0.9)$ & $2(3.1)$ \\
\hline Long-term use of high-dose corticosteroids & $17(5.9)$ & $14(6.2)$ & $3(4.7)$ \\
\hline Fracture after age of 50 years & $26(9.0)$ & $2(10.2)$ & $3(4.7)$ \\
\hline Age $>70$ years & $65(22.4)$ & $3(14.2)$ & $33(51.6)$ \\
\hline Age $>60$ years & $109(37.6)$ & $78(34.5)$ & $31(48.4)$ \\
\hline Hip fracture in first-degree family member & $41(14.1)$ & $28(12.4)$ & $13(20.3)$ \\
\hline Weight $<60$ kg & $44(15.2)$ & $41(18.1)$ & $3(4.7)$ \\
\hline Severe immobility & $28(9.7)$ & $19(8.4)$ & $9(14.1)$ \\
\hline Risk score $\geq 4$ & $43(14.8)$ & $38(16.8)$ & $5(7.8)$ \\
\hline \multicolumn{4}{|l|}{ Diagnosis according to DXA, $n(\%)$} \\
\hline Osteoporosis & $41(14.1)$ & $32(14.2)$ & $9(14.1)$ \\
\hline Osteopenia & $146(50.3)$ & $117(51.8)$ & $29(45.3)$ \\
\hline Normal bone density & $103(35.5)$ & $77(34.1)$ & $26(40.6)$ \\
\hline
\end{tabular}

differences in sex, age, or socioeconomic status between non-responders and participants (data not shown). Two hundred and twenty-eight females and 65 males filled out the questionnaire; 232 females

Table 3. Total risk score according to the case-finding instrument and osteoporosis diagnosis according to dual energy X-ray absorptiometry.

\begin{tabular}{lccc} 
& Osteoporosis & No osteoporosis & $n$ \\
\hline \multicolumn{2}{l}{ Total population: $\boldsymbol{n}=\mathbf{2 9 0}$} \\
\hline Risk score $\geq 4$ & 8 & 35 & 43 \\
\hline Risk score $<4$ & 33 & 214 & 247 \\
\hline$n$ & 41 & 249 & 290 \\
\hline Females: $\boldsymbol{n}=\mathbf{2 2 6}$ & & & \\
\hline Risk score $\geq 4$ & 7 & 31 & 38 \\
\hline Risk score $<4$ & 25 & 163 & 188 \\
\hline$n$ & 32 & 194 & 226 \\
\hline Males: $\boldsymbol{n}=\mathbf{6 4}$ & & & \\
\hline Risk score $\geq 4$ & 1 & 4 & 5 \\
\hline Risk score $<4$ & 8 & 51 & 59 \\
\hline$n$ & 9 & 55 & 64 \\
\hline
\end{tabular}

$D X A=$ dual energy $X$-ray absorptiometry.

Table 4. Sensitivity, specificity, PPV, and NPV of the Dutch case-finding instrument for referral of patients with osteoporosis for DXA measurement.

\begin{tabular}{|c|c|c|c|c|}
\hline & $\begin{array}{c}\text { Sensitivity \% } \\
(95 \% \mathrm{Cl})\end{array}$ & $\begin{array}{c}\text { Specificity \% } \\
(95 \% \mathrm{Cl})\end{array}$ & $\begin{array}{l}\text { PPV \% } \\
(95 \% \mathrm{Cl})\end{array}$ & $\begin{array}{l}\text { NPV \% } \\
(95 \% \mathrm{Cl})\end{array}$ \\
\hline $\begin{array}{l}\text { Total population } \\
(n=290)\end{array}$ & $\begin{array}{c}19.5 \\
\text { (7.4 to } 31.6)\end{array}$ & $\begin{array}{c}85.9 \\
\text { (81.6 to } 90.3)\end{array}$ & $\begin{array}{c}18.6 \\
\text { (7.0 to } 30.2)\end{array}$ & $\begin{array}{c}86.6 \\
\text { (76.5 to } 96.8)\end{array}$ \\
\hline $\begin{array}{l}\text { Males } \\
(n=64)\end{array}$ & $\begin{array}{c}11.1 \\
(-9.4 \text { to } 31.6)\end{array}$ & $\begin{array}{c}92.7 \\
\text { (85.9 to } 99.6)\end{array}$ & $\begin{array}{c}20.00 \\
(-15.1 \text { to } 55.1)\end{array}$ & $\begin{array}{c}86.4 \\
\text { (56.4 to 116.4) }\end{array}$ \\
\hline $\begin{array}{l}\text { Females } \\
(n=226)\end{array}$ & $\begin{array}{c}21.9 \\
\text { (7.6 to } 36.2)\end{array}$ & $\begin{array}{c}84.0 \\
(78.9 \text { to } 89.2)\end{array}$ & $\begin{array}{c}18.4 \\
(6.1 \text { to } 30.7)\end{array}$ & $\begin{array}{c}86.7 \\
\text { (75.9 to } 97.5)\end{array}$ \\
\hline
\end{tabular}

$P P V=$ positive predictive value. $N P V=$ negative predictive value. and 64 males underwent DXA measurement. Only participants who completed both DXA measurement and the questionnaire were included for analyses: 226 females and 64 males. Table 2 summarises the results. Of all participants, $15 \%(43 / 290)$ scored at least four points on the questionnaire -38 females and five males. According to DXA results and $\mathrm{WHO}$ criteria, $14 \%(41 / 290)$ of all participants had osteoporosis (32 females and nine males). Osteopenia was found in $50 \%(146 / 290)$ of participants (117 females and 29 males). Of all participants, $36 \%(103 / 290)$ had normal bone mineral density: 77 females and 26 males.

Of the 41 osteoporotic patients, eight (20\%) scored at least 4 points on the questionnaire (seven females and one male). Results are summarised in Table 3 for the whole population, females, and males.

\section{Statistics}

In Table 4 sensitivity, specificity, PPV, and NPV of the case-finding instrument are shown using a cut-off score $\geq 4$. Regarding the $\mathrm{WHO}$ diagnostic criteria for osteoporosis, the case-finding instrument had a sensitivity of $19.5 \%$, a specificity of $85.9 \%$, a PPV of $18.6 \%$, and NPV of $86.6 \%$.

Analyses based on the Dutch diagnostic criteria for osteoporosis (using Z scores for DXA results from participants aged $>70$ years) resulted in rather similar findings for the total population (sensitivity $17.4 \%$, specificity $85.6 \%$, PPV $14.0 \%$, and NPV $88.3 \%$ ), and for females as well as for males (data not shown).

\section{DISCUSSION}

\section{Summary of main findings}

In this study, the sensitivity, specificity, and predictive value of the Dutch case-finding instrument for the selection of patients with osteoporosis for DXA measurement were evaluated. Although specificity 
(85.9\%) and NPV (86.6\%) were appropriate, sensitivity and PPV were low: $19.5 \%$ and $18.6 \%$ respectively.

\section{Strengths and limitations of the study}

A strength of the study is that a response rate of $67 \%$ suggests no recall bias. However, the community is a rural area, and only white participants were included. This might explain why the prevalence of osteoporosis in the research population is rather low compared to the overall prevalence of osteoporosis. Hence, the results cannot be generalised to the whole Dutch population. Another limitation of the study is that, due to its cross-sectional design, no information is provided on the usefulness of the Dutch case-finding instrument in enhancing fracture prevention in participants with osteoporosis. However, it is likely that the accuracy for fracture prevention will also be unsatisfying, as bone mineral density is an important risk factor for fractures in participants without a previous fracture. In addition, only 64 males were included. Because of limited power, no definite conclusions regarding data of this subgroup can be drawn.

\section{Comparison with existing literature}

As already mentioned, other case-finding instruments to select patients for DXA measurement have been developed and validated. In Table 5 the construct validity of some of these is shown and compared to that of the current study. ${ }^{9-19}$ Although sensitivity of the majority of these instruments is high, most are limited by moderate specificity and PPV. The Dutch case-finding instrument showed the poorest outcomes. An aspect that might contribute to the low sensitivity of the Dutch case-finding instrument is the nature of risk factors that have been included. For example, one may speculate what the relevance is of asking a patient whether he or she suffers from a vertebral fracture, knowing that up to two-thirds of vertebral fractures are clinically unrecognised. ${ }^{22}$ Moreover, the question concerning severe immobility has not been quantified. Neither item is used in other instruments.

Another aspect is the use of the weighted scores in the Dutch case-finding instrument. It is remarkable that the definitions of the weighted scores of the Dutch instrument are based on the relative risk of certain factors for hip and vertebral fractures (as defined by the Dutch Institute for Health Care Improvement ${ }^{5}$ ), instead of risk of factors for low bone mineral density. Moreover, compared to other casefinding instruments, different weights have been attributed to several risk factors. For example, being aged between 60 and 70 years is regarded as a small risk for osteoporosis in the Dutch instrument, while in
Table 5. Sensitivity, specificity, PPV, and NPV of case-finding tools for $\mathrm{T}$ score $\leq \mathbf{- 2 . 5}$.

\begin{tabular}{lccccc}
$\begin{array}{l}\text { Case-finding } \\
\text { instrument }\end{array}$ & $\begin{array}{c}\text { 1st author, year } \\
\text { of publication }\end{array}$ & $\begin{array}{c}\text { Sensitivity } \\
\%\end{array}$ & $\begin{array}{c}\text { Specificity } \\
\%\end{array}$ & $\begin{array}{c}\text { PPV } \\
\%\end{array}$ & $\begin{array}{c}\text { NPV } \\
\%\end{array}$ \\
\hline Dutch instrument $^{19}$ & Elders, 2005 & 20 & 86 & 19 & 87 \\
\hline ABONE $^{9}$ & Cadarette, 2001 & 83 & 48 & & \\
\hline OPERA $^{10, a}$ & Salaffi, 2005 & $88-90$ & $61-64$ & $29-39$ & $96-97$ \\
\hline ORAI $^{11}$ & Cadarette, 2000 & 94 & 41 & 18 & \\
\hline OSIRIS $^{12,13}$ & Sedrine, 2002 & 79 & 51 & & \\
& Reginster, 2004 & 85 & 39 & 42 & 83 \\
\hline OST $^{14-16, b}$ & Richy, 2004 & 86 & 40 & 41 & 86 \\
& Adler, 2003 & 75 & 80 & 41 & 95 \\
\hline SCORE $^{17}$ & Koh, 2001 & 91 & 45 & & \\
\hline Weight criterion $^{18, a}$ & Sedrine, 2001 & 98 & 19 & 7 & 99 \\
\hline
\end{tabular}

${ }^{\mathrm{a}} \mathrm{T}$ scores of lumbar spine and femoral neck separately. ${ }^{\mathrm{b}} \mathrm{Cut}$-off -1. PPV $=$ positive predictive value. $N P V=$ negative predictive value. $A B O N E=A g e, B O d y$, No Estrogen use. OPERA = Osteoporosis Prescreening Risk Assessment. ORAI = Osteoporosis Risk Assessment Instrument. OSIRIS = Osteoporosis Index of Risk. OST = Osteoporosis Selfassessment Tool. SCORE = Simple Calculated Osteoporosis Risk Estimation.

other instruments the factor 'age' has received much more weight.

\section{Implications for clinical practice and future research}

The low value of PPV indicates that the chance is low that a patient, who scores $\geq 4$ points, indeed suffers from osteoporosis. An instrument with moderate PPV can be used in practice, if the sensitivity is high and (thus) the majority of patients with a high risk profile are identified. However, as both PPV and sensitivity of the Dutch case-finding instrument are low, a substantial number of patients with osteoporosis are missed. In fact, for every patient that is diagnosed with osteoporosis after referral for DXA, based on a high-risk score, about five patients with osteoporosis remain undiscovered (in males this would be eight patients).

The clinical impact of these findings is important because the Dutch guidelines are used on a large scale in general practice. In the same period and in the same area as the present study, a large osteoporosis project, supported by health insurance, was conducted. Within this project, GPs used the Dutch case-finding instrument to detect patients at high risk for osteoporosis, and referred them for DXA measurement. Over 21500 participants were included. By using the Dutch case-finding instrument, it can be concluded from the current study that the majority of patients with osteoporosis have been missed and are thus denied appropriate treatment. Although several other large GP centres intend to set up similar casefinding projects, health insurance companies are at present rather reluctant to collaborate. 
It can be argued that the Dutch College of General Practitioners never meant their guidelines to be used as a case-finding instrument, especially not on a large scale. However, by introducing an instrument with weighted indices and a cut-off score above which patients should be referred for DXA, the Dutch strategy does resemble a diagnostic tool rather than general guidelines. Moreover, whether or not the Dutch guidelines are used for an individual patient or a large population, the likelihood of missing a patient with osteoporosis, with the resulting clinical impact, remains the same.

It can be concluded that the Dutch case-finding instrument, which is widely used in general practice in the Netherlands, is of little value for selecting patients for DXA measurement. However, the growing incidence of osteoporosis reflects the urge for an active strategy towards fracture prevention. Further research is needed to develop a more appropriate policy to detect patients at risk for osteoporosis. In addition, follow-up research is warranted to evaluate the usefulness of case-finding instruments for the prevention of fractures.

\section{Ethical approval}

Not applicable.

\section{Competing interests}

The authors have stated that there are none

\section{Acknowledgements}

We are indebted to the insurance company $\mathrm{CZ}$ for their permission to perform the DXAs.

\section{Discuss this article}

Contribute and read comments about this article on the Discussion Forum: http://www.rcgp.org.uk/bjgp-discuss

\section{REFERENCES}

1. Poole K, Compston J. Osteoporosis and its management. BMJ 2006; 333(7581): 1251-1256

2. Kanis JA, Johnell O. Requirements for DXA for the management of osteoporosis in Europe. Osteoporos Int 2005; 16(3): 229-238.

3. Woolf $\mathrm{AD}$, Akesson K. Preventing fractures in elderly people. $B M$ J 2003; 327(7406): 89-95.

4. Hofman A, Boerlage PA, Bots ML, et al. Prevalence of chronic diseases in the elderly; the ERGO study (Erasmus Rotterdam Health and the Elderly). Ned Tijdschr Geneeskd 1995; 139(39): 1975-1978.

5. Kwaliteitsinstituut voor de gezondheidszorg CBO. Osteoporose: tweede herziene richtlijn. Alphen a/d Rijn: Van Zuiden Communications, 2002.

6. Kanis JA, Burlet N, Cooper C, et al. European Society for Clinical and Economic Aspects of Osteoporosis and Osteoarthritis (ESCEO). European guidance for the diagnosis and management of osteoporosis in postmenopausal women. Osteoporos Int 2008; 19 399-428.

7. Kanis JA, Borgstrom F, De Laet C, et al. Assessment of fracture risk. Osteoporos Int 2005; 16(6): 581-589.

8. Genant HK, Cooper C, Poor G, et al. Interim report and recommendations of the World Health Organization Task-Force for Osteoporosis. Osteoporos Int 1999; 10(4): 259-264.

9. Cadarette SM, Jaglal SB, Murray TM, et al. Evaluation of decision rules for referring women for bone densitometry by dual-energy X-ray absorptiometry. JAMA 2001; 286(1): 57-63.

10. Salaffi F, Silveri F, Stancati A, Grassi W. Development and validation of the osteoporosis prescreening risk assessment (OPERA) tool to facilitate identification of women likely to have low bone density. Clin Rheumatol 2005; 24(3): 203-211.

11. Cadarette SM, Jaglal SB, Kreiger N, et al. Development and validation of the Osteoporosis Risk Assessment Instrument to facilitate selection of women for bone densitometry. CMAJ 2000; 162(9): 1289-1294.

12. Sedrine WB, Chevallier T, Zegels B, et al. Development and assessment of the Osteoporosis Index of Risk (OSIRIS) to facilitate selection of women for bone densitometry. Gynecol Endocrinol 2002; 16(3): 245-250.

13. Reginster JY, Ben Sedrine W, Viethel P, et al. Validation of OSIRIS, a prescreening tool for the identification of women with an increased risk of osteoporosis. Gynecol Endocrinol 2004; 18(1): 3-8.

14. Richy F, Gourlay M, Ross PD, et al. Validation and comparative evaluation of the osteoporosis self-assessment tool (OST) in a Caucasian population from Belgium. QJM 2004; 97(1): 39-46.

15. Adler RA, Tran MT, Petkov VI. Performance of the Osteoporosis Selfassessment Screening Tool for osteoporosis in American men. Mayo Clin Proc 2003; 78(6): 723-727.

16. Koh LK, Sedrine WB, Torralba TP, et al. Osteoporosis Self-Assessment Tool for Asians (OSTA) Research Group. A simple tool to identify Asian women at increased risk of osteoporosis. Osteoporos Int 2001; 12: 699-705.

17. Sedrine BW, Devogelaer JP, Kaufman JM, et al. Evaluation of the simple calculated osteoporosis risk estimation (SCORE) in a sample of white women from Belgium. Bone 2001; 29(4): 374-380.

18. Michaëlsson K, Bergström R, Mallmin $\mathrm{H}$, et al. Screening for osteopenia and osteoporosis: selection by body composition. Osteoporos Int 1996; 6(2): 120-126.

19. Elders PJ, Leusink GL, Graafmans WC, et al. NHG standaard osteoporose. Huisarts Wet 2005; 48: 559-570.

20. Anonymous. Osteoporosis: review of the evidence for prevention, diagnosis and treatment and cost-effectiveness analysis. Introduction. Osteoporos Int 1998; 8 (Suppl 4): S7-S80.

21. Anonymous. Assessment of fracture risk and its application to screening for postmenopausal osteoporosis. Report of a WHO Study Group. World Health Organ Tech Rep Ser 1994; 843: 1-129.

22. Kanis JA, McCloskey EV. Epidemiology of vertebral osteoporosis. Bone 1992; 13 (Suppl 2): S1-S10. 